\title{
PACKAGING OF HEPATITIS B SURFACE ANTIGEN VACCINE AND MORINGA OLEIFERA EXTRACT INTO CHITOSAN NANOPARTICLES
}

\author{
DIKY MUDHAKIR ${ }^{1 *}$, ADIK AHMADI ${ }^{1}$, MUHAMAD INSANU ${ }^{1}$, NENY NURAINI ${ }^{2}$ \\ ${ }^{1}$ Department of Pharmaceutics, School of Pharmacy, Institut Teknologi Bandung, Bandung, Indonesia. ${ }^{2}$ Biofarma Limited Company, \\ Bandung, Indonesia. Email: mudhakir@fa.itb.ac.id
}

Received: 26 September 2016, Revised and Accepted: 17 November 2018

\section{ABSTRACT}

Objective: Oftentimes, the recombinant antigen for the use of vaccines is less immunogenic than live attenuated or inactive vaccines. Hence, a potent adjuvant is needed to enhance the immune response. Moreover, the role of vector design is also important to facilitate the improvement of the immune response. The aim of this research was to develop hepatitis B surface antigen (HBsAg)-loaded nanoparticles and Moringa oleifera aqueous leaf extracts as an adjuvant using chitosan polymer.

Methods: Chitosan nanoparticles were prepared by the ionic gelation method using sodium tripolyphosphate as the cross-linking agent. A system was composed of chitosan core in which HBsAg and M. oleifera extracts were incorporated. The concentration of HBsAg used in this combination was $10 \mu \mathrm{g} / \mathrm{ml}$, and the concentrations of extracts were 10,50 , and $100 \mu \mathrm{g} / \mathrm{ml}$, respectively. In this study, three types of nanoparticles were produced: HBsAg-loaded nanoparticles, $M$. oleifera-loaded nanoparticles, and combination of HBsAg-M. oleifera-loaded nanoparticles. The nanoparticles formed were characterized by the particle size, HBsAg entrapment efficiency using sodium dodecyl sulfate polyacrylamide gel electrophoresis, and the entrapment efficiency of extracts using the total flavonoid method.

Results: The results showed that the particle size was between 111 and $245 \mathrm{~nm}$. The entrapment efficiency of HBsAg in the separate formula was $79 \%$, while that in the combined formula was approximately $96-98 \%$. Furthermore, the entrapment efficiency of the extracts in the separate formula was around 64-91\%, while that in the combined formula was 55-82.5\%. Particularly, HBsAg-M. oleifera-loaded chitosan nanoparticles with the extract concentrations of $50 \mu \mathrm{g} / \mathrm{ml}$ showed the highest entrapment efficiencies of $\mathrm{HBsAg}$ and $M$. oleifera extracts of approximately 98 and $82.5 \%$, respectively.

Conclusion: Collectively, the system has been successfully developed, so it is then plausible to determine the function of the devices to enhance the immune response in the future.

Keywords: Nanoparticle, Chitosan, Hepatitis B surface antigen, Adjuvant, Moringa oleifera.

(C) 2019 The Authors. Published by Innovare Academic Sciences Pvt Ltd. This is an open access article under the CC BY license (http://creativecommons. org/licenses/by/4. 0/) DOI: http://dx.doi.org/10.22159/ajpcr.2019.v12i1.15386

\section{INTRODUCTION}

Hepatitis B is a type of deadly viral disease caused by the hepatitis B virus (HBV). Approximately 4.5 million new HBV infections occur every year in the world. In Indonesia, the results of basic medical research in 2007 showed the prevalence of hepatitis B at 9.4\%, which means that at least one in ten of the Indonesian population had been infected with hepatitis B or approximately 23 million people from the total population of Indonesia. After an acute infection, infants and adults, who become infected with the HBV carrier that has been carrying the disease for years and at a later stage, referred to the occurrence of cirrhosis and hepatocellular carcinoma [1].

The prevention of chronic viral hepatitis B has become a top priority for the global community. An approach was prepared by activating the appropriate immune response during chronic viral infection. Immunization with hepatitis B vaccine is the best preventive measure against infection. However, the hepatitis B vaccine can be available in parenteral dosage forms. It is not very effective because parenteral vaccines only stimulate the systemic immune response and the produced antibody cannot reach the mucosal surface, which is the main entry point of most infectious pathogens [2]. Oral vaccine delivery has a distinct advantage over traditional injected vaccines because it induces both a systemic and mucosal immune response, whereas the injected vaccine only leads to serum antibody production. Stimulating an immune response at the mucosal site is very desirable because many pathogens enter the body at this site. If an immune response occurs at the mucosal site, the pathogen can be prevented from even entering the body [3]. However, the vaccine administered orally has low bioavailability. Therefore, to boost the immune response and to administer oral vaccines, adjuvants and suitable delivery systems are required.

It has been reported that the ethanol extracts of Moringa oleifera had the immunostimulatory activity. Extracts of $250 \mathrm{mg}$ of weight increased the activity of the macrophage phagocytic index by approximately $2.85 \pm 0.81$ [4]. Meanwhile, another study reported that M. oleifera leaves have immunomodulatory activity. The aqueous extracts of $M$. oleifera at a concentration of $0.1 \mathrm{mg} / \mathrm{ml}$ increased the number of cluster of differentiation $4+(\mathrm{CD} 4+)$ cells and Cluster of differentiation $8+($ CD $8+$ ) cells by approximately $54.49 \%$ and $15.57 \%$, respectively. It is then believed that $M$. oleifera plays an important role in immune stimulation [5]. Recently, it was reported that $M$. oleifera extracts were loaded into gelatin nanoparticles [6]. However, there is still no report regarding the encapsulation of hepatitis B surface antigen (HBsAg) and $M$. oleifera extracts in nanoparticles. This research aimed to develop nanoparticle hepatitis B (HBsAg) vaccine using the chitosan polymer and to use plant-derived adjuvant for the vaccine delivery systems. Particularly, in the first stage, the ability of HBsAg and M. oleifera extracts to be packaged in the nanostructured vesicles was studied.

\section{MATERIALS AND METHODS}

Materials

M. oleifera extracts were purchased from Megasetia, Indonesia. Toluene, ethanol, sitroborate, sodium tripolyphosphate (STPP), acetic 
acid, sodium hydroxide, methanol, aluminum chloride $\left(\mathrm{AlCl}_{3}\right)$, acetic sodium, quercetin, and sodium dodecyl sulfate polyacrylamide gel electrophoresis (SDS-PAGE) were purchased from Sigma-Aldrich. The total percentage of acrylamide (T-acrylamide) 30\%, Temed, and silver staining reagent was purchased from Thermo Fisher Scientific. HBsAg was kindly received from Bio Farma, Indonesia.

\section{Methods}

\section{Examination of water content}

The level of water examination was performed with the toluene distillation method. $200 \mathrm{ml}$ of toluene was added in a distillation flask, and $7 \mathrm{ml}$ of water was also added into the flask and heated until the toluene was saturated. The toluene number was recorded. $2 \mathrm{~g}$ of simplisia was put into the flask containing the saturated toluene and heated until the water was completely evaporated. The change in toluene numbers was recorded. In the examination of the water content of $M$. oleifera extracts, approximately $100 \mathrm{mg}$ of the extracts were weighed and analyzed by the Karl Fischer titrator using reagents of hydranal methanol dry and CombiTitrant.

\section{Drying losses examination}

The examination of the losses by drying was done by means of the Moisture Balance. Simplisia or extracts were weighed and put into the apparatus and heated at a temperature of $105^{\circ} \mathrm{C}$. The weight of the simplisia was recorded before and after the examination. Then, the level of drying losses was then calculated.

\section{Inspection of chromatogram pattern}

The mobile phase consisted of chloroform and methanol that was prepared in a ratio of 9:1. $10 \mathrm{ml}$ of mobile phase was put into the chamber and saturated. Simplisia was dissolved in ethanol followed by a filtration process. Quercetin was independently dissolved in ethanol. $10 \mu \mathrm{l}$ of simplisia solution as well as quercetin solution was applied on the thin-layer chromatography (TLC) plate in the chamber and eluted by the mobile phase. The TLC plate was dried and sprayed with Borocitric solution, followed by heating at $100^{\circ} \mathrm{C}$ for $2 \mathrm{~min}$. Spots of chromatogram pattern were detected under ultraviolet (UV) light at a wavelength of $366 \mathrm{~nm}$. To check the chromatogram pattern of $M$. oleifera extracts, the procedure was similar to that of simplisia as described above, except that the ratio of mobile phase of chloroform to methanol was approximately 8:2.

\section{Determination of total flavonoid content}

About $50 \mathrm{mg}$ of simplisia was dissolved in methanol to obtain a concentration of $5000 \mu \mathrm{g} / \mathrm{ml}$ and then filtered to remove the remaining undissolved simplisia. $0.5 \mathrm{ml}$ of this solution was added with $1.5 \mathrm{ml}$ of methanol, $0.1 \mathrm{ml}$ of $10 \% \mathrm{AlCl}_{3}$, and $0.1 \mathrm{ml}$ of $1 \mathrm{M}$ sodium acetate and then incubated in a dark room for $30 \mathrm{~min}$. The sample was then analyzed by an UV-visible spectrophotometer at a maximum wavelength of $432 \mathrm{~nm}$.

\section{Preparation of chitosan nanoparticles carrying HBsAg and M. oleifera extracts}

Chitosan was dissolved in $1 \%$ acetic acid $(\mathrm{v} / \mathrm{v})$ to form a concentration of $1.4 \mathrm{mg} / \mathrm{ml}$ with a $\mathrm{pH}$ of 5 . STPP was dissolved in distilled water to form a concentration of $1.47 \mathrm{mg} / \mathrm{ml}$. HBsAg concentration of $10 \mu \mathrm{g} / \mathrm{ml}$ along with extract concentrations of 10,50 , and $100 \mu \mathrm{g} / \mathrm{mL}$ was incubated with a chitosan solution of $\mathrm{pH} 5$ for $30 \mathrm{~min}$. Nanoparticles were spontaneously formed through the ionotropic gelation process. Technically, $250 \mu \mathrm{l}$ of the STPP solution was added dropwise to a $750 \mu$ l of chitosan solution containing HBsAg and extracts using a $1 \mathrm{ml}$ syringe. It was then stirred at room temperature using a magnetic stirrer. The suspension was centrifuged at 13,000 rpm for $10 \mathrm{~min}$, and the supernatant was collected to determine the entrapment efficiencies of HBsAg and the extracts. The precipitates were redispersed in $100 \mu$ l of deionized water and sonicated at $60 \mathrm{~Hz}$ for $10 \mathrm{~s}$. Then, the final nanoparticles suspension was characterized.

Characterization of particle size and polydispersity index

Particle size analysis was performed using DelsaTM NanoC (Beckman Coulter). The instrument can measure particle sizes in the range of $0.6 \mathrm{~nm}-7 \mu \mathrm{m}$, with an optimum concentration of $0.001 \%-40 \%$.
Determination of the entrapment efficiency of $\mathrm{HBsAg}$

The entrapment efficiency was determined through an indirect method by measuring the amount of free HBsAg that was unencapsulated in the nanoparticles. The HBsAg assay was done using silver staining on SDS-PAGE gel with the silver PROTEO kit and observed by a densitometer. The concentration of SDS gel used was $12 \%$. The SDS gel was prepared in two stages, separating the gel preparation and the stacking gel. After the gel was formed, the sample supernatant was mixed with a sample buffer (2:1) and then denatured using a thermomixer (temperature $95^{\circ} \mathrm{C}, 300 \mathrm{rpm}, 5 \mathrm{~min}$ ). It was then added to the SDS gel through the wall of the stacking gel and run for $80 \mathrm{~min}$ at a power of $120 \mathrm{~V}$. Silver staining was performed using a silver PROTEO kit, including fixation, sensitization, silver equilibrium, development, and stopping reaction in an incubator shaker $\left(20^{\circ} \mathrm{C}, 60 \mathrm{rpm}\right)$. The gels were scanned using a densitometer and analyzed using Image-J program to determine the efficiency of the entrapment.

\section{Determination of entrapment efficiency of $M$. oleifera extracts}

The entrapment efficiency of the extracts was also determined through an indirect method by measuring the amount of extract that was unencapsulated in the nanoparticles. We tracked quercetin in the free extracts as a marker through total flavonoid method to reflect the amount of free extracts. The supernatant was separated, and $0.5 \mathrm{ml}$ of supernatant was added with $1.5 \mathrm{ml}$ of methanol, $0.1 \mathrm{ml}$ of $10 \%$ $\mathrm{AlCl}_{3}, 0.1 \mathrm{ml}$ of $1 \mathrm{M}$ sodium acetate, and distilled water. Due to the low absorbance of the samples, we utilized the addition method in the test by adding known concentrations of quercetin. The concentrations of quercetin were $5,7.5$, and $10 \mu \mathrm{g} / \mathrm{ml}$, respectively. The samples were incubated in the dark room for $30 \mathrm{~min}$ and analyzed with a UV-Vis spectrophotometer at a maximum wavelength of $432 \mathrm{~nm}$.

\section{RESULTS AND DISCUSSION}

This study presented the packaging of HBsAg and M. oleifera into nanoparticles in which the chitosan polymer was used. It has recently been demonstrated that silver nanoparticles (AgNPs) were synthesized from the leaf extracts of $M$. oleifera [7]. However, the toxicity of particularly AgNPs to various organisms, such as Pseudomonas putida, Escherichia coli, Daphnia magna, and Chlamydomonas reinhardtii, is undeniable [7]. It has also been suggested that the three major mechanisms of AgNPs toxicity appear to directly damage cell membranes, generate reactive oxygen species, and release Ag ions [8]. Therefore, in this study, we focused on the use of biodegradable polymers such as chitosan to encapsulate HBsAg and M. oleifera extracts, whose degradation polymers cannot be harmful and ensure removal from the body.

\section{Characterization of simplisia and extracts of $M$. oleifera}

This study aimed to investigate the ability of nanoparticles to encapsulate HBsAg and M. oleifera extracts in the same structure to accommodate HBsAg vaccine for enhancing its immune response. Previously, we examined the standardization of $M$. oleifera simplisia according to the requirements of the Indonesian Herbal Pharmacopoeia. As a result, the simplisia have met the requirements based on test parameters and microscopic studies, and thus, it can be extracted for its use as an adjuvant (Table 1).

In the case of the standardization of $M$. oleifera extracts, it was based on a chromatogram pattern of the ethanol extracts of its leaves. On the basis of the results of the chromatogram pattern, it is likely that the pattern of the extracts is similar to that of simplisia (Fig. 1). The results

Table 1: Simplisia Characteristic Data

\begin{tabular}{lll}
\hline Test parameters & Results (\%) & Requirements \\
\hline Drying losses & $7.06 \pm 0.04$ & Not $>12 \%$ \\
Water content & $5.25 \pm 0.35$ & Not $>10 \%$ \\
Total flavonoid level & $1.42 \pm 0.06$ & Not $<0.5 \%$ \\
\hline
\end{tabular}

Values represent mean $\pm \mathrm{SD}, \mathrm{n}=3$ 


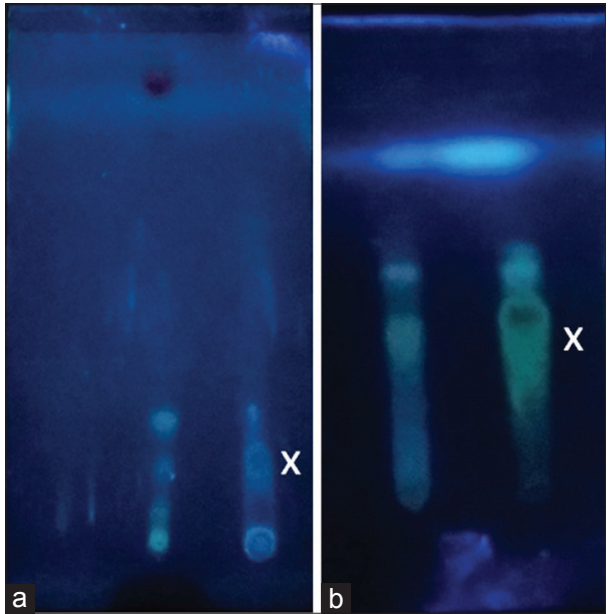

Fig. 1: Chromatogram pattern of (a) simplisia with $\mathrm{Rf} 0.27$ and (b) Moringa oleifera extracts with $\mathrm{Rf} 0.49$. Left lane=quercetin marker, right lane=sample

Table 2: Characteristics of nanoparticles

\begin{tabular}{llll}
\hline No & Formula & $\begin{array}{l}\text { Particle } \\
\text { size }(\mathbf{n m})\end{array}$ & $\begin{array}{l}\text { Polydispersity } \\
\text { index }\end{array}$ \\
\hline 1. & Empty nanoparticles & $111.1 \pm 8.5$ & $0.051-0.277$ \\
2. & Nano-HBsAg $10 \mu \mathrm{g} / \mathrm{ml}$ & $143.8 \pm 18.7$ & $0.172-0.346$ \\
3. & Nano-M. oleifera $10 \mu \mathrm{g} / \mathrm{ml}$ & $221.9 \pm 13.1$ & $0.251-0.277$ \\
4. & Nano-M. oleifera $50 \mu \mathrm{g} / \mathrm{ml}$ & $239.7 \pm 25.9$ & $0.160-0.392$ \\
5. & Nano-M. oleifera $100 \mu \mathrm{g} / \mathrm{ml}$ & $244.6 \pm 49.1$ & $0.052-0.278$ \\
6. & Nano-HBsAg+M. oleifera $10 \mu \mathrm{g} / \mathrm{ml}$ & $181.8 \pm 33.1$ & $0.173-0.356$ \\
7. & Nano-HBsAg+M. oleifera $50 \mu \mathrm{g} / \mathrm{ml}$ & $219.8 \pm 50.5$ & $0.195-0.327$ \\
8. & Nano-HBsAg+M. oleifera $100 \mu \mathrm{g} / \mathrm{ml}$ & $219.2 \pm 52.4$ & $0.182-0.224$ \\
\hline
\end{tabular}

Values of particle size represent mean $\pm S D, n=3$ and data of polydispersity index represents range, $M$. oleifera: Moringa oleifera, HbsAg: Hepatitis B surface antigen

indicate that the extraction method is suitable to ensure the quality under the requirements. In addition, other examination parameters of the aqueous extracts of $M$. oleifera were performed as a quality control of the extracts. The results of yield, drying losses, and water content of the extracts were $17.44 \%, 9.79 \pm 0.23 \%$, and $8.24 \pm 0.82 \%$, respectively. The results of the drying losses and water content of the aqueous extracts also meet the requirements of the Indonesian Herbal Pharmacopoeia.

The total flavonoid content test result was $0.77 \pm 0.03 \%$. Our data were comparable with previous data, showing that the total flavonoid level of aqueous extracts of $M$. oleifera leaves was $0.95 \pm 0.07 \%$ [9]. The determination of total flavonoid levels is one of the important parameters since flavonoids such as kaempferol, rhamnetin, isoquercetin, and kaempferitrin are natural immunomodulators that play a role in increasing the immune response [10,11]. M. oleifera leaves are also known to be rich in quercetin, glycosides, kaempferol, and saponin if we compare with another part of the plant, such as the bark. It also has been used in the Ayurveda and Unani medicine system for a long time $[12,13]$. In general, the standardized parameters of the extracts fulfilled the pharmacopeia requirements and the extracts were allowed to be investigated for packaging into the nanostructured particles.

\section{Preparation of chitosan nanoparticles}

The preparation of chitosan nanoparticles as an antigen carrier matrix was performed using the ionotropic gelation method. It is based on the interaction between the positive charge of the protonated $\mathrm{NH}_{2}$ moiety of chitosan in an acid solution that forms $\mathrm{NH}^{3+}$ and a negative charge of the polyanion STPP as a cross-linker [14]. We characterized the nanoparticles in terms of particle size and polydispersity index. The produced chitosan nanoparticles had a size in the range of 111-245 nm (Table 2). When the empty nanoparticles were incorporated by HBsAg, the size of the nanoparticles increased significantly. Moreover, when $M$. oleifera extracts were loaded into the nanoparticles, the particle size was even larger. These results indicate that the size of HBsAg is smaller than that of M. oleifera extracts. It is well known that the size of HBsAg was merely 20-33 nm [15]. Thus, our data are in line with the fact of the HBsAg size in which the empty nanoparticles had a size of $111 \mathrm{~nm}$ and the particles were enhanced by approximately $144 \mathrm{~nm}$ when HBsAg was loaded into the particles.

Moreover, the combination of HBsAg and M. oleifera extracts loaded with chitosan nanoparticles was smaller in size than the extracts of merely $M$. oleifera encapsulated in the particles. Presumably, the extracts have a low molecular weight and a single dimension of conformation compared to the virus-like particle (VLP) of HBsAg. When HBsAg was encapsulated into the chitosan nanoparticles along with the M. oleifera extracts, it is likely that the extracts enter the inner space of the HBsAg VLP and also interacts with chitosan through covalent bonding resulting in a smaller particle size [16]. Based on the previous study, the low molecular weight of memantine hydrochloride-loaded nanoparticle had a particle size of around $203 \mathrm{~nm}$ in an STPP and chitosan ratio of approximately 1:3 [17]. In line with our study using a similar system, the results emphasized on the efficiency of the encapsulation since the particles were comparable in size with the previous report, even though we packaged a combination of low molecular weight of HBsAg and high molecular weight of M. oleifera extract compounds in the same vesicle. This was due to the formation of nanoparticles that depend on the stirring speed and intermolecular cross-linking between STPP and chitosan in the preparation of nanoparticles [18-20]. In this study, we used a stirring rate at $800 \mathrm{rpm}$, which was lower than the previously reported $1000 \mathrm{rpm}$ [17]. It was clearly shown that the particle size distribution was significantly narrowed by increasing the stirring rate from 200 to $800 \mathrm{rpm}$. Furthermore, the increase in the stirring rate at $1000 \mathrm{rpm}$ leads to an aggregate formation [18]. It is hypothesized that an adequate stirring rate accelerates the dispersion of STPP in the chitosan solution and the increase in shear forces improves the monodispersity, while an intense stirring rate may destroy the repulsive force between the particles and lead to aggregation of the particles.

In addition, we added STPP dropwise to the chitosan solution in the preparation of nanoparticles. This method prevented intermolecular crosslinking that leads to a larger particle size. It has been explained that the formation of aggregates leading to the formation of larger particles depends on the contact time between the particles when they collide $[19,20]$. Time is also essential to obtain a permanent chain entanglement between the particles when they spontaneously crosslink to form a microgel through the interaction between the positive charge of chitosan and the negative charge of STPP $[19,20]$. Therefore, it is likely that the role of stirring rate and STPP addition technique is important in this study to package HBsAg and M. oleifera extracts.

Particle size plays an important role in the nanoparticle delivery system. Magnocellular cells (M cells) in the follicle-associated epithelium intestinal Peyer's patches are oral vaccine delivery targets, and hence, the formula should facilitate that the preparations are absorbed by the $M$ cells. If the particle size is $<1 \mu \mathrm{m}$, it is internalized and systemically transported to the $\mathrm{M}$ cells, which potentially generates a systemic immune response. As for the large-sized particles, they will remain in the intestinal epithelium for an immune response to appear as a local immune response [21]. Based on the results of the particle size in Table 2, it seems that the particle size has a potential to be internalized in the $\mathrm{M}$ cells to provide a systemic immune response.

The particle size distribution is expressed as a polydispersity index. The results obtained from the polydispersity index study ranged from 0.05 to 0.39 . The results reveal that the produced nanoparticles have reasonably good physical stability. The acceptable value of the 
polydispersity index is from 0 (monodisperse particles) to 0.5 (wide particle size distribution). The low polydispersity index indicates that the formed dispersion system is more stable in the long term [22].

\section{Entrapment efficiency of HBsAg}

The entrapment efficiency of HBsAg was determined using an indirect method by measuring HBsAg unencapsulated in the nanoparticles. It was examined using silver staining on SDS-PAGE. In this method, the gel was stained with silver dye and scanned with a densitometer to capture the density in the image. As a result, nanoparticles containing a combination of HBsAg and $M$. oleifera extracts with the same concentration of $10 \mu \mathrm{g} \mathrm{ml}$ provided the highest entrapment efficiency of approximately $98.59 \%$ (Table 3 ). The lowest one was given by the $10 \mu \mathrm{g} \mathrm{ml} \mathrm{HBsAg}$ nanoparticles. It is possible that the small size of the HBsAg-loaded nanoparticles of approximately $144 \mathrm{~nm}$ limits the entrapment of HBsAg, where it shapes VLP with a size of 20-33 nm. In addition, the results of the captured image from SDS-PAGE showed that there was a slight monomer band that appeared in the supernatant samples (Fig. 2, lanes 3-6). Those were having sizes of $26 \mathrm{kDa}$, which have the same size as HBsAg standard marker. Thus, it is likely that it reflected a minor unencapsulated HBsAg. Since the encapsulation efficiency of HBsAg was high of a minimum of $96 \%$, the packaging of HBsAg was considered successful. In nanoparticles encapsulating the combination w HBsAg and M. oleifera extracts, the entrapment efficiency of HBsAg was concomitant with an increase in the concentration of the extracts. This suggests that there is a possibility of competition between the HBsAg and the extracts to be located in the chitosan-based nanoparticles.

Table 3: Entrapment efficiencies of HBsAg and M. oleifera extracts in nanoparticles

\begin{tabular}{llll}
\hline \multirow{2}{*}{ No } & Formula & Entrapment efficiency (\%) \\
\cline { 3 - 4 } & & HBsAg & $\begin{array}{l}\text { M. oleifera } \\
\text { extracts }\end{array}$ \\
\hline & & $79.47 \pm 5.62$ & - \\
\hline 1. & Nano-HBsAg $10 \mu \mathrm{g} / \mathrm{ml}$ & - & $63.91 \pm 31.27$ \\
2. & Nano-M. oleifera $10 \mu \mathrm{g} / \mathrm{ml}$ & - & $90.86 \pm 7.14$ \\
3. & Nano-M. oleifera $50 \mu \mathrm{g} / \mathrm{ml}$ & - & $88.69 \pm 7.67$ \\
4. & Nano-M. oleifera $100 \mu \mathrm{g} / \mathrm{ml}$ & $98.59 \pm 6.48$ & $55.41 \pm 39.98$ \\
5. & Nano-HBsAg+M. oleifera $10 \mu \mathrm{g} / \mathrm{ml}$ \\
6. & Nano-HBsAg+M. oleifera $50 \mu \mathrm{g} / \mathrm{ml}$ & $97.85 \pm 7.85$ & $82.56 \pm 26.02$ \\
7. & Nano-HBsAg+M. oleifera $100 \mu \mathrm{g} / \mathrm{ml}$ & $95.95 \pm 6.43$ & $76.51 \pm 24.12$ \\
\hline
\end{tabular}

Values represent mean \pm SD, $n=3$, M. oleifera: Moringa oleifera, HbsAg: Hepatitis B surface antigen

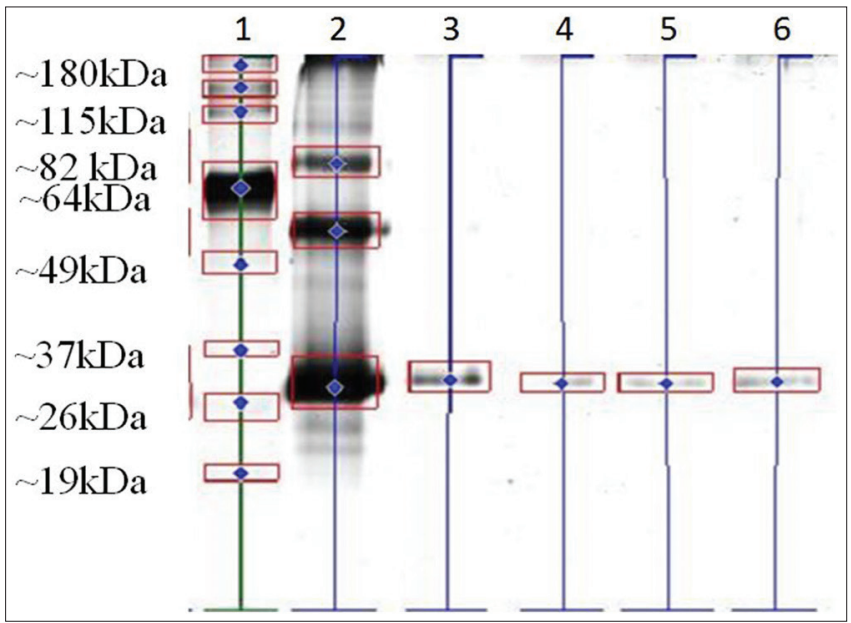

Fig. 2: Results of SDS-PAGE of chitosan nanoparticle compared to standard HBsAg. (1) Ladder, (2) Standard HBsAg, (3) Nano HBsAg $10 \mu \mathrm{g} / \mathrm{ml}$, (4) Nano HBsAg $10 \mu \mathrm{g} / \mathrm{ml}+$ M. oleifera extracts $10 \mu \mathrm{g} / \mathrm{ml}$, (5) Nano HBsAg $10 \mu \mathrm{g} / \mathrm{ml}+$ M. oleifera extracts $50 \mu \mathrm{g} / \mathrm{ml}$, (6) Nano HBsAg $10 \mu \mathrm{g} / \mathrm{ml}+$ M. oleifera extracts $100 \mu \mathrm{g} / \mathrm{ml}$.

\section{ENTRAPMENT EFFICIENCY OF M. OLEIFERA EXTRACTS}

The aqueous extract of $M$. oleifera was highly entrapped in the chitosan-based nanoparticles in a range of $64-91 \%$. It seemed that the highest entrapment efficiency of $91 \%$ was provided by the use of the concentration of $M$. oleifera extracts of $50 \mu \mathrm{g} / \mathrm{ml}$. Furthermore, in the case of the entrapment efficiency of $M$. oleifera extracts in the nanoparticles loaded with a combination of HBsAg and the extracts, it showed a high level of approximately a range of $55-82.5 \%$. The highest entrapment efficiency was also obtained using the concentration of extracts of $50 \mu \mathrm{g} / \mathrm{ml}$. Thus, the maximum entrapment capacity of the extracts having a concentration of $50 \mu \mathrm{g} /$ $\mathrm{ml}$ was shown. Basically, the competition between HBsAg and $M$. oleifera extracts occurs in the nanoparticles so that, particularly in the case of combination, the entrapment efficiency was lower than that of a single compound. Our results show that the high entrapment efficiency of $M$. oleifera extracts is $91 \%$, which is better than previous studies. It was reported that the gelatin nanoparticles encapsulated with $M$. oleifera extracts had an entrapment efficiency of around 83\% [5]. Meanwhile, our results showed a comparable entrapment efficiency of $M$. oleifera of approximately $82.5 \%$, and especially, it is in combination with HBsAg, which also showed a high entrapment efficiency of $98 \%$. To the best of our knowledge, this is the first report of packaging two compounds of HBsAg vaccine and $M$. oleifera extracts in the same nanostructure. The potential function of the produced chitosan-based nanoparticles loaded with HBsAg-M. oleifera extracts in enhancing the immune response of HBsAg needs to be clarified in the future.

\section{CONCLUSION}

The results of the present study concluded that the HBsAg vaccine along with the aqueous extracts of M. oleifera was successfully packaged in the chitosan-based nanostructured particles with highly entrapment efficiencies of HBsAg and M. oleifera extracts.

\section{ACKNOWLEDGMENT}

This work was supported by the Research Grant of the Institut Teknologi Bandung Development Project (III) of the Japan International Cooperation Agency, Japan.

\section{REFERENCES}

1. Arora D, Khurana B, Kumar MS, Vyas S. Oral immunization againts hepatitis B virus using mannosylated bilosomes. Int J Rec Adv Pharm Res 2011;1:45-51.

2. Zho F, Neutra MR. Antigen delivery to mucosa-associated lymphoid tissues using liposomes as a carrier. Biosci Rep 2002;22:355-69.

3. Das S, Desmukh R. Advances in vaccination: A review. Int J Appl Pharm 2009;1:1-21.

4. Galuh AS. Pengaruh pemberian ekstrak Phyllanthus niruri L terhadap fungsifagositosismakrofag pada mencitBALb/c yang diinfeksi Salmonella typhimurium. Semarang: Fakultas Kedokteran Universitas Diponegoro; 2008

5. Rachmawati I, Muhaimin R. In vitro immunomodulatory activity of aqueous extract of Moringa oleifera Lam. Leaf to CD4+, CD8+, B220+ cells in Mus musculus. J Exp Life Sci 2014;4:15-20.

6. Hani N, Azarian MH, Torkamani AH, Mahmood WA. Characterization of gelatin nanoparticles encapsulated with Moringa oleifera bioactive extract. Int J Food Sci Technol 2016;51:2327-37.

7. Moodley JS, Krishna SB, Pillay K, Sershen N, Govender P. Green synthesis of silver nanoparticles from Moringa oleifera leaf extracts and its antimicrobial potential. Adv Nat Sci Nanosci Nanotechnol 2018:9:1-9.

8. Choi Y, Kim HA, Kim KW, Lee BT. Comparative toxicity of silver nanoparticles and silver ions to Escherichia coli. J Environ Sci 2018;66:50-60.

9. Vongsak B, Sithisarn S, Mangmool S, Thongpraditchote S, Wongkrajang Y, Gritsanapan W. Maximizing total phenolics, total flavonoid contents, and antioxidant activity of Moringa oleifera leaf extract by the appropriate extract method. Ind Corps Prod 2012;44:566-71. 
10. Bennet RN, Mellon FA, Foidl N, Pratt JH, Dupont MS, Perkins L, et al. Profiling glucosinolates and phenolics in vegetative and reproductive tissues of multi-purpose trees Moringa oleifera Lam. and Moringa stenopetala L. J Agric Food Chem 2003;51:3546-53.

11. Bose CK. Possible role of Moringa oleifera Lam root in epithelial ovarian cancer. Med Gen Med 2004;9:26.

12. Anwar F, Latiff S, Ashraf M, Gillani AH. Moringa oleifera: A food plant with multiple medicinal uses. Phytother Res 2007;21:17-25.

13. Sarvesh K, Kumar MS, Ankit S, Kumar SA. Quality control standardization of the bark of Moringa oleifera Lam. Int J Pharm Pharm Sci 2015;7:34-7.

14. Tiyaboonchai W. Chitosan nanoparticles: A promising system for drug delivery. Naresuan Univ J 2003;11:51-66

15. Diminsky D, Schirmbeck R, Reimann J, Barenholz Y. Comparison between HBsAg particles derived from mammalian cells (CHO) and yeast cells: Composition, structure and immunogenicity. Vaccine 1997; 15:637-47.

16. Hu B, Pan C, Sun Y, Hou Z, Ye H, Zeng X. Optimization of fabrication parameters to produce chitosan-tripolyphosphate nanoparticles for delivery of tea catechin. J Agric Food Chem 2008;56:7451-8.

17. Ruby JJ, Pandey VP. Chitosan nanoparticles as a nasal drug delivery for memantine hydrochloride. Int J Pharm Pharm Sci 2015;7:56-60.

18. Fan W, Yan W, Xu Z, Ni H. Formation mechanism of monodisperse, low molecular weight chitosan nanoparticles by ionic gelation technique. Colloid Surf B 2012;90:21-7.

19. Jonassen H, Kjeniksen AL, Hiorth M. Effects of ionic strength on the size and compactness of chitosan nanoparticles. Colloid Polym Sci 2012;290:919-29.

20. Kaloti M, Bohidar HB. Kinetics of coacervation transition versus nanoparticle formation in chitosan-sodium tripolyphosphate solutions. Colloid Surf B 2010;81:165-75.

21. Slütter B, Plapied L, Fievez V, Sande MA, des Rieux A, Schneider YJ, et al. Mechanistic study of the adjuvant effect of biodegradable nanoparticles in mucosal vaccination. $J$ Control Release 2009;138:113-21.

22. Gao L, Zhang D, Chen M. Drug nanocrystals for formulation of poorly soluble drugs and its application as potential drug delivery system. J Nanopart Res 2008;10:845-62 